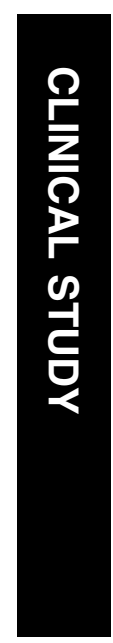

\section{Bilateral lateral rectus recession considering the tendon width in intermittent exotropia}

H Lee and S-H Kim
Department of

Ophthalmology, Korea University College of Medicine, Seoul, Korea

Correspondence: S-H Kim, Department of Ophthalmology, Korea University Ansan Hospital, 516 Gojan-dong, Gyunggi-do, 425-707, South Korea Tel: + 8231 412-5160; Fax: + 82314148930 E-mail: ansaneye@ hanmail.net

Received: 9 December 2008 Accepted in revised form: 16 April 2009 Published online: 15 May 2009

This study was presented at $32^{\text {nd }}$ Meeting of the European Strabismological Association, 2008, Germany

\begin{abstract}
Purpose The tendon width of the lateral rectus muscle can be a useful indicator of the effect of unilateral lateral rectus recession in intermittent exotropia. ${ }^{1}$ The aim of this study was to determine whether the tendon width of lateral rectus would be useful for predicting the effect of bilateral lateral rectus (BLR) recession.

Methods We studied a total of 45 patients between 3 and 15 years of age who had undergone bilateral rectus recession for the basic type of intermittent exotropia. The actual effect of lateral recession was calculated by adding the absolute value of the angle of preoperative deviation and the postoperative deviation on the second day and dividing the figure by the total amount of recession. We then calculated the hypothetical effect of lateral rectus recession, considering the tendon width of each eye, and added the effects of both eyes. The hypothetical effects were defined as 3 PD when the tendon width was $8-8.5 \mathrm{~mm}$; 3.5 PD when it was $7-7.5 \mathrm{~mm}$; and $2.5 \mathrm{PD}$ when it was 9-9.5 mm, based upon earlier statistical analysis. ${ }^{1}$ We compared both effects using a paired $t$-test.

Results The mean difference between the actual and the hypothetical effects of BLR recession in all patients was $2.88 \mathrm{PD}(P=0.001$, range: 0-5.50 PD). However, when the amount of preoperative exodeviation was below $25 \mathrm{PD}$, the differences were not statistically significant $(P=\mathbf{0 . 0 8 6})$.

Conclusion The tendon width may also be useful indicator in BLR recession if the preoperative exodeviation is below $25 \mathrm{PD}$. Eye (2009) 23, 1808-1811; doi:10.1038/eye.2009.113; published online 15 May 2009
\end{abstract}

Keywords: bilateral lateral rectus recession; tendon width; intermittent exotropia; desired overcorrection; excessive innervation; contracture

\section{Introduction}

In patients with intermittent exotropia, there is a tendency towards exotropic drift over time because of the high rate of undercorrection. The prevalence of overcorrection after surgery has been reported to be $6-20 \% .^{2-4}$

Overcorrection of exotropia in the early postoperative period, on the other hand, gives the best long-term results for intermittent exotropia. A surgical recession table modified from Parks is used for determining the optimal surgical dosage. ${ }^{5}$ According to this table, the effect of the $1 \mathrm{~mm}$-lateral rectus recession is about 3 PD. However, there are various factors that may significantly influence surgical outcomes for the surgeon to consider, including age at surgery, exotropia type, amount of stereopsis, high $\mathrm{AC} / \mathrm{A}$ ratio and lateral incomitancy. ${ }^{6-13}$

The tendon width of the lateral rectus can be a useful indicator to estimate the effect of lateral rectus recession in intermittent exotropia. The mean effect of the $1 \mathrm{~mm}$ lateral rectus recession has been shown to range from 2.7 to $3.5 \mathrm{PD}$, according to the tendon width. The effect of recession has been shown to be larger in cases in which the lateral rectus tendon width is narrower. One of the authors has reported this earlier in patients who underwent unilateral lateral rectus recession for the basic type of intermittent exotropia. ${ }^{1}$

The aim of this study was to determine whether the tendon width of the lateral rectus would predict the effects of bilateral lateral 
rectus (BLR) recession to facilitate the appropriate amount of overcorrection as the surgeon desires in the early postoperative period.

\section{Patients and methods}

This prospective study investigated consecutive patients who underwent bilateral $5-8 \mathrm{~mm}$ rectus recession for intermittent exotropia by a single surgeon (SK). We studied 45 patients ranging from 3 to 15 years of age who had undergone BLR recession for the basic type of intermittent exotropia. Patients who had undergone earlier strabismus surgery; those who were younger than 3 years of age; those with myopia, hyperopia, or anisometropia $>2 \mathrm{D}$; those with amblyopia and corrected vision worse than 20/25; and those with lateral incomitance of $>5$ PD were excluded from the study.

All patients underwent complete ophthalmic examinations. Prism and alternate cover tests were carried out at distances of $6 \mathrm{~m}$ and $30 \mathrm{~cm}$ in primary gaze. Under general anaesthesia, the lateral rectus tendon widths were measured in both eyes near the insertion points using calipers, before dissection of the muscle tendon from the sclera. Patients underwent 5-8 mm BLR recession. We aimed for postoperative alignment of approximately 10 PD esodeviation on the second postoperative day. To determine the actual effect of lateral recession, we added the absolute value of the angle of preoperative deviation and the postoperative deviation on the second day and divided this figure by the total amount of recession. We then calculated the

Table 1 Effect of lateral rectus recession according to tendon width

\begin{tabular}{lcc}
\hline $\begin{array}{l}\text { Tendon width } \\
(\mathrm{mm})\end{array}$ & $\begin{array}{c}\text { Effect of earlier } \\
\text { study }\end{array}$ & $\begin{array}{c}\text { Hypothetical effect } \\
(\mathrm{PD} / \mathrm{mm})\end{array}$ \\
\hline $7-7.5$ & $3.5 \pm 0.40$ & 3.5 \\
$8-8.5$ & $2.9 \pm 0.24$ & 3.0 \\
$9-9.5$ & $2.7 \pm 0.26$ & 2.5 \\
\hline
\end{tabular}

hypothetical effect of lateral rectus recession based on the tendon width in each eye and added the effects of both eyes. The hypothetical effects were defined as 3 PD when the tendon width was $8-8.5 \mathrm{~mm}$; 3.5 PD when it was $7-7.5 \mathrm{~mm}$; and 2.5 PD when it was $9-9.5 \mathrm{~mm}$, based on earlier statistical analysis (Table 1).

\section{Statistical analysis}

Age as a demographic characteristic, recession amount, tendon width, preoperative and postoperative deviations were compared between the two groups by the use of independent $t$-tests. Actual effect and hypothetical effect of recession were compared by paired $t$-tests. A $P$-value of $<0.05$ was considered statistically significant.

\section{Results}

Forty-five patients who met the inclusion criteria were divided into two groups: 26 patients had $\leqslant 25$ PD exodeviation (Group A), and 19 patients had > 25 PD exodeviation (Group B) (Table 2).

The overall mean lateral rectus tendon widths were $8.14 \mathrm{~mm}$ OD and $8.02 \mathrm{~mm}$ OS $(P=0.357$, range:

$7-9.5 \mathrm{~mm}$ ). The effect of recession has been shown to be larger in cases in which the lateral rectus tendon width is narrower in this study (Figure 1, Table 3). The mean difference between the actual and hypothetical effects of BLR recession for all patients was $2.88 \mathrm{PD}(P=0.001$, range: $0-5.5 \mathrm{PD}$ ). This means that, there was a significant discrepancy between the actual and hypothetical effects of recession. However, when considering the amount of preoperative deviation in Group A, the differences were not statistically significant $(P=0.085)$.

The mean age of the patients in group A was 5.9 years (range: 3-11 years). The mean preoperative exo-angle in primary gaze was $25.6 \pm 1.71 \mathrm{PD}$ (range 25-30 PD), and the mean esodeviation on the second postoperative day was $8.1 \pm 3.61$ PD (range ortho-10 PD). The mean tendon width was $8.2 \pm 0.59 \mathrm{~mm}$ (range $7-9.5 \mathrm{~mm}$ ), and the mean

Table 2 Subgroup analysis of bilateral rectus recession according to tendon width

\begin{tabular}{|c|c|c|c|}
\hline & Group $A(\leqslant 25$ PD) & Group B (>25 PD) & P-value \\
\hline Age (years) & $6.3 \pm 2.3$ & $7.6 \pm 4.2$ & 0.183 \\
\hline Recession amount (mm) & $5.8 \pm 0.4$ & $7.0 \pm 0.5$ & 0.000 \\
\hline Tendon width $(\mathrm{mm})$ & $8.2 \pm 0.6$ & $8.1 \pm 0.6$ & 0.330 \\
\hline Preoperative deviation (PD) & $24.5 \pm 1.4(20-25)$ & $33.4 \pm 3.5(30-40)$ & 0.000 \\
\hline Postoperative deviation (PD) ${ }^{\mathrm{a}}$ & $9.2 \pm 2.7(0-14)$ & $5.9 \pm 3.1(0-12)$ & 0.002 \\
\hline Actual effect of recession (PD) & $33.8 \pm 3.5$ & $33.4 \pm 3.5$ & 0.001 \\
\hline Hypothetical effect of recession (PD) & $36.1 \pm 2.8$ & $45.2 \pm 3.6$ & 0.000 \\
\hline$P$-value $\mathrm{b}^{\mathrm{b}}$ & 0.086 & 0.001 & \\
\hline
\end{tabular}

${ }^{\mathrm{a} B y}$ independent $t$-test.

${ }^{\mathrm{b}}$ By paired- $t$ test. 


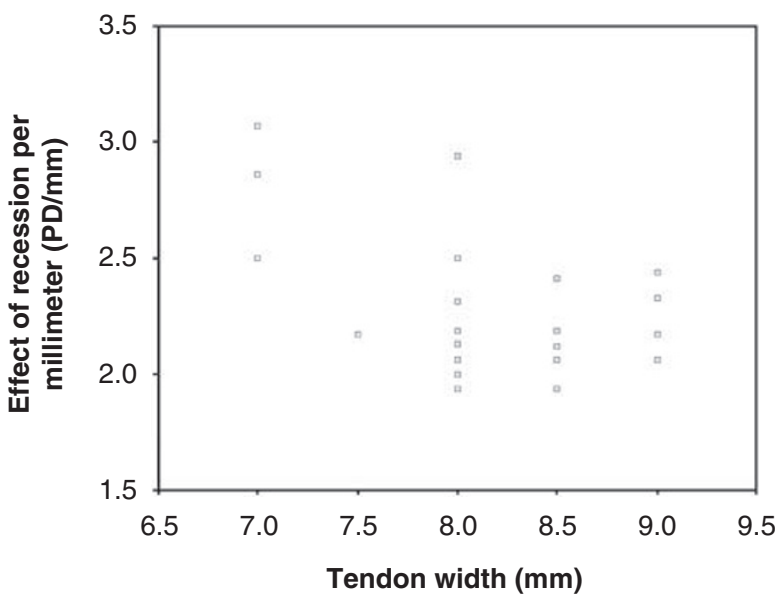

Figure 1 Graph depicting the relation between the tendon widths and the effects of lateral rectus recession per millimetre in 38 patients except seven patients who have asymmetry of the tendon width. $(r=0.545, P=0.003)$.

Table 3 Differences in tendon width in both eyes

\begin{tabular}{lcc}
\hline Difference $(\mathrm{mm})$ & Group A ( $\leqslant 25$ PD) & Group B (>25 PD) \\
\hline 0 & $12(46.2 \%)$ & $11(57.9 \%)$ \\
0.5 & $10(38.5 \%)$ & $5(26.3 \%)$ \\
1.0 & $2(7.7 \%)$ & $3(15.8 \%)$ \\
1.5 & $2(7.7 \%)$ & $0(0 \%)$ \\
\hline
\end{tabular}

magnitude of recession was $6.0 \pm 0.44 \mathrm{~mm}$. The mean effect of bilateral rectus recession in those patients was $33.8 \pm 3.44 \mathrm{PD}$, and the hypothetical effect was $36.1 \pm 2.78$ PD $(P=0.085)$

The mean age of the patients in group B was 7.4 years (range: 3-11). The mean preoperative exodeviation in primary gaze was $33.4 \pm 3.52 \mathrm{PD}$ (range $30-40 \mathrm{PD}$ ), and the mean esodeviation on the second postoperative day was $5.9 \pm 3.14$ PD (range 2-12 PD). The mean tendon width was $8.1 \pm 0.63 \mathrm{~mm}$ (range 7-9 $\mathrm{mm}$ ), and the mean magnitude of recession was $7.23 \pm 0.46 \mathrm{~mm}$. The mean effect of bilateral rectus recession in those patients was $39.3 \pm 3.53 \mathrm{PD}$, and the hypothetical effect was $45.2 \pm 3.59$ PD $(P=0.007)$. The hypothetical effect in group $B$ tended to be overestimated, so that the desired overcorrection was not reached (Table 2).

\section{Discussion}

Regarding the surgical management of exotropia, there is a widespread agreement that the initial overcorrection is needed because, there is a tendency towards postoperative exotropic drift. Raab and Parks ${ }^{4}$ reported that an overcorrection of $10 \mathrm{PD}$ to $20 \mathrm{PD}$ provided the best outcome. Scott $e t a^{14}$ advised an overcorrection of between 4 PD and 14 PD. Good correlations between the initial and final measurements after surgery for intermittent exotropia have been reported by other investigators. ${ }^{15,16}$

The aim of this study was to determine how to achieve the magnitude of overcorrection the surgeon desires (10 PD) in the early postoperative period and to provide information to surgeons regarding the amount of lateral rectus recession required in the intermittent exotropia.

The effect of the lateral rectus recession is approximately 3 PD per millimetre. However, we noted earlier that the effects of recession were larger in cases in which the tendon width of the lateral rectus was decreased. The effects of lateral rectus recession according to the tendon width range is from 2.7 PD to 3.5 PD. The authors noted that an earlier excessive innervation to the lateral recti can lead to hypertrophy and that the tendon width of lateral rectus might speak for the hypertrophy of the muscles. ${ }^{1,17}$ Therefore, the effects of the lateral rectus recession increase as the tendon width decreases, even though the differences are subtle.

In this study, recession effects related to the tendon width could also be applied when the magnitude of exodeviation was $\leqslant 25$ PD. However, when exodeviation was $>25 \mathrm{PD}$, there was a significant discrepancy between the actual and hypothetical effects of recession, so that the surgical intervention failed to bring the deviation within 5 PD of the target amount of overcorrection in the early postoperative period. The hypothetical effects in group B of the current study tended to be overestimated; therefore, the desired overcorrection was not reached. We could not explain this phenomenon exactly, but it may suggest the presence of progression of fibrosis and LR contracture in largeangle exotropia, besides the tendon width factor. Bielschowsky ${ }^{18}$ found that the functional contractures from anatomically changed extraocular muscles are retained by excessive innervation. Contracture is associated with loss of elasticity related to histological alterations consisting of atrophy of muscle fibres, and hyalinization of the normal muscle. This process progresses gradually over time, so in longstanding strabismus the agonistic muscles undergo hypertrophy and develop fibrosis and contracture. ${ }^{19}$ Even though the age difference was small between groups $A$ and $B$, the patients in group $B$ were older than those in group $A$.

Additionally, it is difficult to calculate the effects of the BLR recession considering the tendon width, because the tendon widths can differ between the eyes. However, 38 (84\%) patients had nearly symmetrical tendon widths ( $<0.5 \mathrm{~mm}$ difference between the eyes). Tendon width asymmetry did not affect the analysis of the effect of recession in this study.

In conclusion, the earlier suggestion that the effect of recession is larger in cases in which the tendon width of 
lateral rectus is narrower may also be applied to BLR recession if the preoperative exodeviation is below 25 PD. We can achieve about 10 PD early overcorrection through BLR recession, considering the tendon width when the preoperative exodeviation is below 25 PD. However, if this principle is being applied to longstanding exotropia, the clinician should consider the effect of muscle contracture and modify the amount of lateral rectus recession.

\section{References}

1 Kim SH, Choi YJ. Effects of unilateral rectus recession according to the tendon width in intermittent exotropia. Eye 2006; 20: 785-788.

2 Hardesty HH, Boynton JR, Keenan JP. Treatment of intermittent exotropia. Arch Ophthalmol 1978; 96: 268-274.

3 Fletcher MC, Silverman SJ. Strabismus. I. A summary of 1,110 consecutive cases. Am J Ophthalmol 1966; 61: 86-94.

4 Kim HS, Suh YW, Kim SH, Cho YA. Consecutive esotropia in intermittent exotropia patients with immediate postoperative overcorrection more than 17 prism diopters. Korean J Ophthalmol 2007; 21: 155-158.

5 Raab EL, Parks MM. Recession of the lateral recti: early and late postoperative alignment. Arch Ophthalmol 1969; 82: 203-208.

6 Pratt-Johnson JA, Barlow JM, Tillson G. Early surgery in intermittent exotropia. Am J Ophthalmol 1977; 84: 689-694.

7 Parks MM. Concomitant exodeviations. In: Duan TD (edn) Clinical Ophthalmology, Ocular motility and Strabismus. Harper and Row: Hagerstown (MD), 1975, pp 113-122.

8 Richard JM, Parks MM. Intermittent exotropia. Surgical results in different age groups. Ophthalmology 1983; 90: 1172-1177.
9 Kushner BJ. Selective surgery for intermittent exotropia based on distant/near differences. Arch Ophthalmol 1998; 116: 324-328.

10 Ing MR, Nishimura J, Okino L. Outcome study of bilateral lateral rectus recession for intermittent exotropia in children. Ophthalmic Surg Lasers 1999; 30: 110-117.

11 Maruo T, Kubota N, Sakaue T, Usui C. Intermittent exotropia surgery in children. long term outcome regarding changes in binocular alignment. A study of 666 cases. Binocul Vis Strabismus Q 2001; 18: 265-270.

12 Beneish R, Flanders M. The role of stereopsis and early postoperative alignment in long-term surgical results in intermittent exotropia. Can J Ophthalmol 1994; 29: 119-124.

13 Yildirim C, Mutlu FM, Chen Y, Altinsoy HI. Assessment of central and peripheral fusion and near and distance stereoacuity in intermittent exotropia patients before and after strabismus surgery. Am J Ophthalmol 1999; 128: 222-230.

14 Scott WE, Keech R, Mash AJ. The postoperative results and stability of exodeviations. Arch Ophthalmol 1981; 99: 1814-1818.

15 Cooper EL. Purposeful overcorrection in exotropia. In: Arruga A (edn). International Strabismus Symposium. Karger: Basel, 1968, pp 311-316.

16 Burian HM. Exodeviations: their classification, diagnosis, and treatment. Am J Ophthalmol 1966; 62: 1161-1166.

17 Jasman W, Jaeger EA. Concomitant exodeviation. In: Parks MM, Mitchell PR (edn). Duane's Clinical Ophthalmology. JB Lippincott company: Philadelphia, Vol 1, Chapter 13, 1991.

18 Bielschowsky A. The etiology of squint. Am J Ophthalmol 1937; 20: 478-489.

19 Noorden GK. Binocular Vision and Ocular Motility, Theory and Management of Strabismus, 6th ed. St Louis: Mosby, 2002; 414-415. 